\title{
Early Decline in Six-Minute Walk Distance from the Time of Diagnosis Predicts Clinical Worsening in Pulmonary Arterial Hypertension
}

\author{
Julie Huang Sanjay Mehta Marco Mura \\ Southwest Ontario Pulmonary Hypertension Clinic, Division of Respirology, Department of Medicine, Schulich \\ School of Medicine and Dentistry, Western University, London, Ont., Canada
}

For editorial comment see p. 363

\section{Key Words}

Pulmonary hypertension - Six-minute walk distance .

Clinical worsening $\cdot$ Outcome $\cdot$ Survival

\begin{abstract}
Background: The six-minute walk distance (6MWD) is commonly used to assess pulmonary arterial hypertension (PAH). However, the role of 6MWD in predicting outcomes in $\mathrm{PAH}$ is controversial. Clinical worsening is being increasingly considered as a clinically meaningful end point in PAH. Objectives: We aimed to investigate whether early longitudinal changes in $6 \mathrm{MWD}(\triangle 6 \mathrm{MWD})$ in meters and percent predicted (\%pred) from the time of diagnosis predict clinical worsening of PAH. Methods: One hundred patients with group I PAH were retrospectively assessed. 6MWD was calculated using American (\%pred US) or Canadian (\%pred CAN) reference equations. $\triangle 6 \mathrm{MWD}$ at 6 months were recorded. Clinical worsening was defined as either: development of right heart failure, hospital admission for PAH, referral for lung transplantation or initiation of prostanoids after oral therapy failed. Optimal 6-month differences in 6MWD to detect worsening were defined with receiver operating characteristics (ROC) analysis. Results: Progressors, i.e. patients with clinical worsening, and nonprogressors showed significant differences in $\triangle 6 \mathrm{MWD}$. The most clinically significant declines in $6 \mathrm{MWD}$ at 6 months were $\geq 35 \mathrm{~m}, \geq 8 \%$ pred US and $\geq 6 \%$ pred CAN. ROC and Cox proportional hazard analyses showed equivalent results for 6 MWD \%pred and meters. Six-month
\end{abstract}

declines in 6MWD predicted worsening with a high specificity (94\%) but a low sensitivity (33\%). Conclusions: Early declines in 6MWD (within the first 6 months) predict future clinical worsening of PAH with high specificity. $\triangle 6 \mathrm{MWD}$ may still be part of a comprehensive assessment of a patient's clinical status. However, given the poor sensitivity, a decline in 6MWD should be used with other clinical tools to make an appropriate assessment of the progression of $\mathrm{PAH}$.

(c) 2015 S. Karger AG, Base

\section{Introduction}

Pulmonary arterial hypertension (PAH) is a condition characterized by vascular remodeling leading to increased pulmonary vascular resistance (PVR), with progression of disease and development of right heart failure. Despite major improvements in the medical therapy for $\mathrm{PAH}$, the prognosis remains poor and the condition is still one of the major indications for lung transplantation (LTx) $[1$, 2].

As significant morbidity and mortality exist despite PAH-targeted therapy, clinically meaningful predictors of clinical worsening are needed. Six-minute walk distance (6MWD) is a commonly used surrogate end point for assessing the clinical status of patients with PAH. Randomized controlled trials (RCTs) have demonstrated that improvements in 6MWD over short periods of time reflect short-term benefits from pharmacotherapy [3-5]. How-

\section{KARGER 125}

C 2015 S. Karger AG Basel

0025-7931/15/0895-0365\$39.50/0

E-Mail karger@karger.com

www.karger.com/res
Marco Mura, MD, $\mathrm{PhD}$

London Health Science Centre, Victoria Hospita

800 Commissioners Road East, Room E6-203

N6A 5W9 London, ON (Canada)

E-Mail marco.mura@lhsc.on.ca 
ever, reports on the overall prognostic performance of the $6 \mathrm{MWD}$ are contrasting, and its association with long-term outcomes has been questioned [6-8]. Another limitation is represented by the 'ceiling effect', i.e. that effective therapy may not further improve exercise capacity in subjects with a relatively preserved baseline 6MWD [9]. Most studies have focused on the improvement in 6MWD as a measure of treatment effect $[7,10,11]$, but despite short-term improvements in 6MWD in response to pharmacotherapy, this has not been correlated with a decreased risk of worsening [12]. In contrast, longitudinal declines in 6MWD as predictors of outcome have received less attention. Moreover, although the 6MWD is highly dependent on patients' variables, studies on $\mathrm{PAH}$ report the absolute $6 \mathrm{MWD}$ value expressed in meters, with only 1 study to date evaluating the percent predicted (\%pred) value, based on the height, weight and age of patients [13].

While there is good evidence that baseline and posttreatment improvements in 6MWD are good predictors of survival $[6,7,14,15]$, it remains unclear whether a decline in 6MWD can predict clinical worsening in PAH. Furthermore, there have been no studies investigating whether 6MWD \%pred is a better predictor of worsening than 6MWD in meters. We hypothesized that an early decline in 6MWD from the time of diagnosis may be a predictor of clinical worsening in $\mathrm{PAH}$, and also assessed the predictive value of $6 \mathrm{MWD} \%$ pred compared to $6 \mathrm{MWD}$ in meters.

\section{Materials and Methods}

Patients diagnosed with World Health Organization (WHO) group I PAH at the Southwest Ontario Pulmonary Hypertension Clinic of the Western University, were retrospectively considered. Baseline was the time of diagnosis. Patients with incomplete data and those with PAH other than group I were excluded. The study was approved by the Research Ethics Board of Western University (protocol No.103784).

$\mathrm{PAH}$ was defined as a mean pulmonary arterial pressure (mPAP) of $\geq 25 \mathrm{~mm} \mathrm{Hg}$ and a pulmonary capillary wedge pressure of $\leq 15 \mathrm{~mm} \mathrm{Hg}$ upon right heart catheterization [16, 17]. Baseline characteristics were captured at the time of diagnosis before the initiation of treatment, and these included age, body mass index (BMI), WHO functional class (WHO FC), 6MWD, right ventricle systolic pressure (RVSP) obtained with echocardiography, mPAP, PVR and the diffusion lung capacity for carbon monoxide (DLCO). After diagnosis, patients received follow-up at intervals of 3-6 months, at the direction of the attending physician. 6MWD was obtained at each follow-up visit, as part of standard of care. 6MWD at 6 months from the time of diagnosis was recorded and changes in $6 \mathrm{MWD}(\triangle 6 \mathrm{MWD})$ were calculated.

The primary end point was clinical worsening of $\mathrm{PAH}$ within 18 months of diagnosis, defined as either: the development of clin- ical features of right heart failure, admission to hospital for PAHrelated respiratory or cardiac causes, initiation of intravenous prostanoids after failing oral therapy or referral for LTx (WHO FC III-IV symptoms in spite of medical therapy or rapidly progressive disease) [18-22]. Worsening-free survival was defined as the interval from the time of diagnosis to clinical worsening. The secondary end point was LTx-free survival, defined as the time from diagnosis to death or LTx.

Pulmonary function tests and 6MWD tests were performed according to the ATS guidelines [23, 24]. 6MWD \%pred was calculated using reference equations based on US and Canadian populations (i.e. \%pred US and \%pred CAN) $[25,26]$.

\section{Statistical Analysis}

Values were expressed as mean \pm standard deviation. Comparisons were made with unpaired Student $t$ tests or Mann-Whitney $U$ tests, where appropriate. Receiver operating characteristics (ROC) analysis was used to determine the cut-off values and longitudinal changes for the detection of the end point. Cut-offs for determining the best 6MWD baseline values to detect the outcome were those that provided the optimal (i.e. the best sum of) sensitivity and specificity (accuracy). Cut-offs for determining the best interval declines of 6MWD to detect the outcome were those that provided the optimal accuracy as well. Time to end point was evaluated using Kaplan-Meier curves and log-rank tests. KaplanMeier distributions were realized with cut-offs from the ROC analysis. Cox proportional hazards regression analysis was used to identify significant variables predicting end points, which were then evaluated with multivariate regression analysis. Results were summarized as hazard ratios (HR). $\mathrm{p}<0.05$ was significant. JMP (SAS Institute, Cary, N.C., USA), GraphPad (MacKiev, San Diego, Calif., USA) and MedCalc (MedCalc, Mariakerke, Belgium) software was used.

\section{Results}

One hundred patients were included. Patients' characteristics at the time of diagnosis are shown in table 1. After diagnosis, patients received PAH-targeted therapies $[16,17]$, including endothelin receptor antagonists (51\%), phosphodiesterase type- 5 inhibitors $(27 \%)$ or a combination of the two (10\%). Six patients were started on intravenous prostanoids at the time of diagnosis. Follow-up from the time of diagnosis was $40 \pm 27$ months.

While 6MWD in meters did not show a significant correlation with mPAP $(\mathrm{r}=-0.20, \mathrm{p}=0.0511), 6 \mathrm{MWD}$ \%pred US $(\mathrm{r}=-0.32, \mathrm{p}=0.0018)$ and \%pred CAN $(\mathrm{r}=$ $-0.32, p=0.0019)$ showed a significant, inverse relationship (online suppl. fig. 1; for all online suppl. material, see www.karger.com/doi/10.1159/000370124). Similarly, a significant, negative correlation was observed between PVR and 6MWD \%pred US and CAN $(\mathrm{r}=-0.28, \mathrm{p}=$ 0.0100 and $\mathrm{r}=-0.23, \mathrm{p}=0.0379$, respectively), but not between 6MWD in meters and PVR $(r=-0.09, \mathrm{p}=0.43)$. 


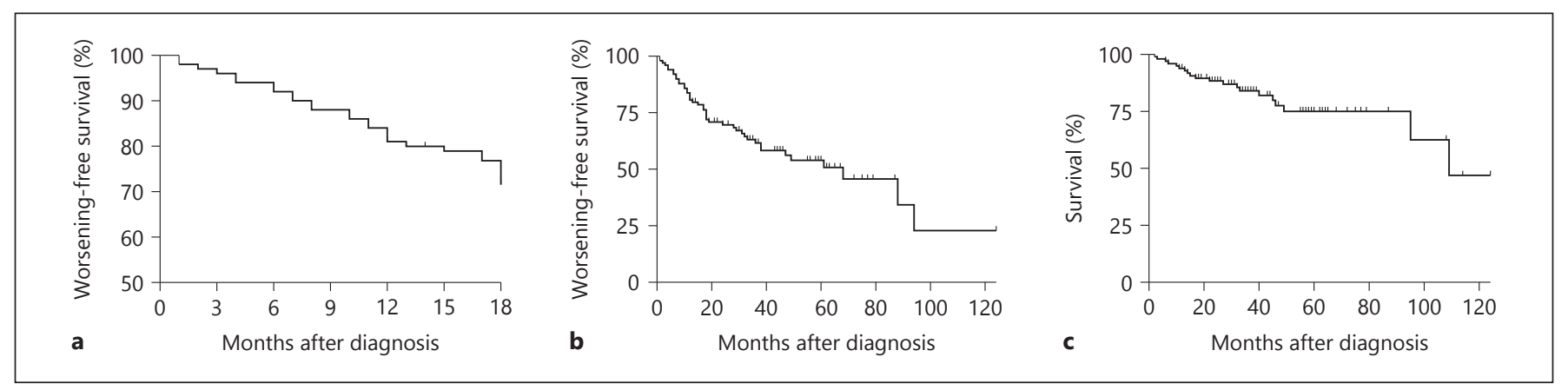

Fig. 1. a Worsening-free survival up to 18 months after diagnosis. b Worsening-free survival. c LTx-free survival.

Table 1. Baseline characteristics of patients included in the study

\begin{tabular}{lc}
\hline Male/female (\% of males) & $76 / 24(24)$ \\
Age at diagnosis, years & $59 \pm 16$ \\
BMI, kg/m ${ }^{2}$ & $29 \pm 8$ \\
Etiology & $50(50)$ \\
$\quad$ Idiopathic PAH & $37(37)$ \\
CTD PAH & $13(13)$ \\
CHD PAH & \\
Function and hemodynamics & $2.8 \pm 0.5$ \\
WHO FC & $49 \pm 18$ \\
DLCO, \%pred & $73 \pm 24$ \\
RVSP, mm Hg & $49 \pm 15$ \\
mPAP, mm Hg & $697 \pm 423$ \\
PVR, dyn-s·cm & \\
6MWD at baseline & $323 \pm 115$ \\
In meters & $67 \pm 22$ \\
\%pred US & $49 \pm 16$ \\
\%pred CAN & \\
6MWD at 6-month follow-up & $334 \pm 127$ \\
In meters & $69 \pm 25$ \\
\%pred US & $50 \pm 18$ \\
\%pred CAN & \\
Therapy started after diagnosis & $51(51)$ \\
ERA & $10(10)$ \\
ERA and PDE5i & $27(27)$ \\
PDE5i & $6(6)$ \\
IV PGI & $3(3)$ \\
Diuretics only & $3(3)$ \\
Calcium-channel blocker &
\end{tabular}

Values are $\mathrm{n}(\%)$ or mean \pm SD. Baseline characteristics were recorded before the initiation of treatment.

$\mathrm{CHD} \mathrm{PAH}=$ Congenital heart disease-associated PAH; CTD PAH $=$ connective tissue disease-associated PAH; ERA = endothelin receptor antagonist; $\mathrm{IV} \mathrm{PGI}_{2}=\mathrm{IV}$ prostacyclin analog; $\mathrm{PDE} 5 \mathrm{i}=$ phosphodiesterase type 5 inhibitor.

Twenty-eight patients (28\%) experienced clinical worsening within 18 months of diagnosis. The average interval from diagnosis to worsening was $10 \pm 6$ months. During the total study period, 19 patients died and 1 received LTx. The average time to death or LTx was $30 \pm 29$ months. Worsening-free survival and LTx-free survival curves are shown in figure 1.

The baseline and longitudinal characteristics of progressors (defined as patients with clinical worsening) versus nonprogressors were compared (table 2; online suppl. table 1). With respect to hemodynamics, mPAP and PVR were significantly higher in progressors. Both 6MWD in meters and \%pred at baseline were significantly different between the groups. The $\triangle 6 \mathrm{MWD}$ from time of diagnosis also showed significant differences: among progressors, a significant decline in 6MWD was observed, compared to non-progressors $[\Delta 6 \mathrm{MWD}(\mathrm{m})]$. ROC analysis was used to determine the baseline cut-off values that best predicted clinical worsening in terms of sensitivity and specificity (fig. 2; table 3). Baseline $6 \mathrm{MWD}$ ( $\leq 342 \mathrm{~m}, \leq 63 \%$ pred US or $51 \%$ pred CAN) all predicted worsening with similar, intermediate sensitivity and specificity. The area under the curve (AUC) was highest for \%pred US (0.71; fig. 2; table 3 ).

ROC analysis determined 6-month $\triangle 6 \mathrm{MWD}$ that best predicted clinical worsening in terms of sensitivity and specificity (fig. 2; table 3; see online suppl. table 2 for a detailed analysis). Declines in 6MWD at 6 months of $\geq 35 \mathrm{~m}, \geq 8 \%$ pred US and $\geq 6 \%$ pred CAN all predicted worsening with exactly the same low sensitivity (33\%) and with high specificity $(94,94$ and $91 \%$, respectively; table 3).

Univariate Cox proportional hazard analysis identified some baseline variables as significant predictors of clinical worsening, including a higher WHO FC, mPAP and PVR, and a lower DLCO (table 4). Age, BMI and RVSP were not predictors of clinical worsening. Considered as continuous variables, a higher baseline \%pred US (HR 0.97) and \%pred CAN (HR 0.96) were more significantly protective towards worsening than $6 \mathrm{MWD}$ in meters (HR 0.99). Similarly, as categorical variables, 6MWDs 
Table 2. Baseline characteristics and 6-month changes comparing progressors (patients who developed clinical worsening) to nonprogressors

\begin{tabular}{|c|c|c|c|}
\hline & $\begin{array}{l}\text { Progressors } \\
(n=28)\end{array}$ & $\begin{array}{l}\text { Non progressors } \\
(\mathrm{n}=72)\end{array}$ & $\mathrm{p}$ value \\
\hline Male/female (\% of males) & $10 / 18(36)$ & $14 / 58(19)$ & n.s. \\
\hline Age at diagnosis, years & $63 \pm 13$ & $57 \pm 17$ & n.s. \\
\hline $\mathrm{BMI}, \mathrm{kg} / \mathrm{m}^{2}$ & $28 \pm 5$ & $30 \pm 8$ & n.s. \\
\hline \multicolumn{4}{|l|}{ Etiology } \\
\hline Idiopathic PAH & $17(61 \%)$ & $34(47 \%)$ & n.s. \\
\hline CTD PAH & $9(32 \%)$ & $28(39 \%)$ & n.s. \\
\hline CHD PAH & $2(7 \%)$ & $10(14 \%)$ & n.s. \\
\hline \multicolumn{4}{|l|}{ Function and hemodynamics } \\
\hline WHO FC & $3.0 \pm 0.2$ & $2.7 \pm 0.5$ & $0.0178^{\mathrm{a}}$ \\
\hline DLCO, \%pred & $43 \pm 19$ & $52 \pm 18$ & n.s. ${ }^{\mathrm{a}}$ \\
\hline RVSP, mm Hg & $77 \pm 28$ & $72 \pm 22$ & n.s. ${ }^{\mathrm{a}}$ \\
\hline mPAP, mm Hg & $57 \pm 15$ & $46 \pm 14$ & $<0.0001$ \\
\hline PVR, dyn $\cdot \mathrm{s} \cdot \mathrm{cm}^{-5}$ & $1,027 \pm 462$ & $549 \pm 309$ & $<0.0001$ \\
\hline \multicolumn{4}{|l|}{ 6MWD at time of diagnosis } \\
\hline In meters & $265 \pm 115$ & $346 \pm 107$ & 0.0012 \\
\hline \%pred US & $55 \pm 22$ & $71 \pm 21$ & 0.0007 \\
\hline \%pred CAN & $41 \pm 16$ & $52 \pm 15$ & 0.0016 \\
\hline \multicolumn{4}{|l|}{ At 6-month follow-up } \\
\hline$\Delta 6 \mathrm{MWD}$ in meters & $-25 \pm 91$ & $23 \pm 43$ & $0.0016^{\mathrm{a}}$ \\
\hline$\Delta 6 \mathrm{MWD} \%$ pred US & $-5 \pm 19$ & $5 \pm 9$ & $0.0022^{\mathrm{a}}$ \\
\hline$\triangle 6 \mathrm{MWD} \%$ pred CAN & $-3 \pm 14$ & $2 \pm 8$ & $0.0157^{\mathrm{a}}$ \\
\hline \multicolumn{4}{|c|}{ Therapy started after diagnosis } \\
\hline ERA & $18(64)$ & $32(44)$ & n.s. \\
\hline ERA and PDE5i & $3(11)$ & $7(10)$ & n.s. \\
\hline PDE5i & $5(18)$ & $23(32)$ & n.s. \\
\hline
\end{tabular}

Values are $\mathrm{n}(\%)$ or mean \pm SD. For abbreviations, see table 1 .

${ }^{a}$ Results obtained with Mann-Whitney U test (see online suppl. table 1 for median and quartiles).

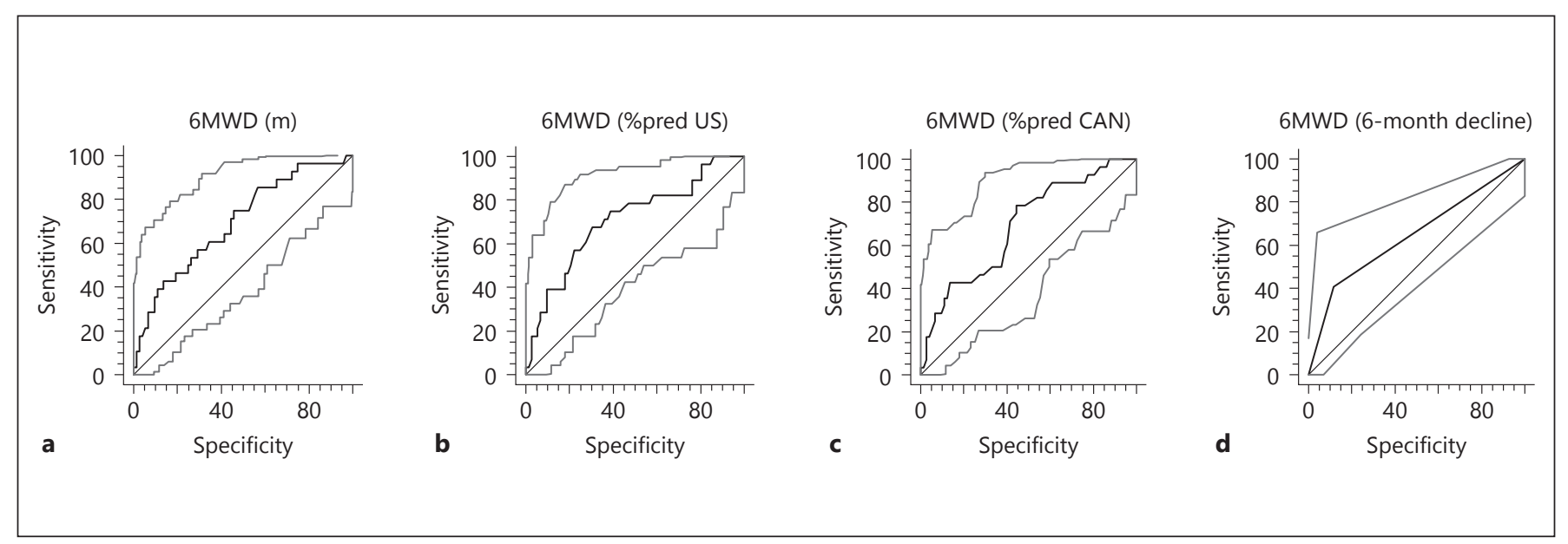

Fig. 2. ROC curves of $6 \mathrm{MWD}$ variables at the time of diagnosis versus upon worsening. See table 3 for further details. a $6 \mathrm{MWD}$ in meters. b $6 \mathrm{MWD} \%$ pred US. c $6 \mathrm{MWD} \%$ pred CAN. d $6 \mathrm{MWD}$ in meters at 6 -month decline (either $\geq 35 \mathrm{~m}$ or $\geq 8 \%$ pred US - results were identical). 
Table 3. ROC analysis of $6 \mathrm{MWD}$ variables at the time of diagnosis versus clinical worsening

\begin{tabular}{lcllll}
\hline Variable & AUC & $\begin{array}{l}\text { Standard } \\
\text { error }\end{array}$ & p value & $\begin{array}{l}\text { Sensitivity, \% } \\
(95 \% \text { CI })\end{array}$ & $\begin{array}{l}\text { Specificity, \% } \\
(95 \% \text { CI })\end{array}$ \\
\hline $\begin{array}{l}\text { Baseline 6MWD } \\
\quad \text { In meters }\end{array}$ & 0.69 & 0.059 & 0.0010 & $75(55-89)$ & $54(42-66)$ \\
$\quad$ \%pred US & 0.71 & 0.060 & 0.0005 & $68(48-84)$ & $69(57-80)$ \\
$\quad$ \%pred CAN & 0.69 & 0.058 & 0.0013 & $79(59-2)$ & $56(43-67)$ \\
6MWD in meters at 6-month decline $(\geq 35 \mathrm{~m})$ & 0.64 & 0.048 & 0.0044 & $33(16-54)$ & $94(86-98)$ \\
6MWD \%pred US at 6-month decline $(\geq 8 \%)$ & 0.64 & 0.048 & 0.0044 & $33(16-54)$ & $94(86-98)$ \\
6MWD \%pred CAN at 6-month decline $(\geq 6 \%)$ & 0.62 & 0.049 & 0.0124 & $33(16-54)$ & $91(82-97)$ \\
\hline
\end{tabular}

The criterion found for baseline 6MWD was $\leq 342 \mathrm{~m}, 63 \%$ pred US and 51\%pred CAN. Abbreviations as in table 1 . See online supplementary table 2 for details on the choice of 6 -month declines. AUC $=$ Area under the curve.

Table 4. Predictors of clinical worsening according to the univariate analysis

\begin{tabular}{llll}
\hline & HR & $95 \%$ CI & p value \\
\hline Age at diagnosis & 1.02 & $0.99-1.05$ & n.s. \\
BMI, kg/m ${ }^{2}$ & 0.98 & $0.92-1.02$ & n.s. \\
WHO FC & 5.61 & $2.06-14.73$ & 0.0005 \\
DLCO, \%pred & 0.97 & $0.95-0.99$ & 0.0320 \\
RVSP, mm Hg & 1.01 & $0.99-1.03$ & n.s. \\
mPAP, mm Hg & 1.04 & $1.01-1.07$ & 0.0022 \\
PVR, dyn·s·cm ${ }^{-5}$ & 1.00 & $1.00-1.00$ & 0.0001 \\
6MWD, m (continuous) & 0.99 & $0.99-0.99$ & 0.0005 \\
6MWD $\leq 342$ m & 3.09 & $1.38-7.85$ & 0.0055 \\
6MWD \%pred US (continuous) & 0.97 & $0.95-0.98$ & 0.0003 \\
6MWD \%pred US ( $\leq 63 \%)$ & 4.01 & $1.63-10.31$ & 0.0014 \\
6MWD \%pred CAN (continuous) & 0.96 & $0.94-0.98$ & 0.0008 \\
6MWD \%pred CAN ( $\leq 51 \%)$ & 3.79 & $1.63-10.31$ & 0.0014 \\
6MWD in meters at 6-month decline $(\geq 35$ m) & 4.86 & $2.07-10.59$ & 0.0006 \\
6MWD \%pred US at 6-month decline $(\geq 8 \%)$ & 4.86 & $2.07-10.59$ & 0.0006 \\
6MWD \%pred CAN at 6-month decline $(\geq 6 \%)$ & 3.87 & $1.65-8.44$ & 0.0027 \\
\hline
\end{tabular}

of $\leq 342 \mathrm{~m}, \leq 63 \%$ pred US and $\leq 51 \%$ pred CAN were associated with a 3.09 -fold $(\mathrm{p}=0.0055), 4.01$-fold ( $\mathrm{p}=$ $0.014)$ and 3.79 -fold $(\mathrm{p}=0.0014)$ risk of worsening, respectively (table 4 ).

A decline in $6 \mathrm{MWD}$ at 6 months of $\geq 35 \mathrm{~m}, \geq 8 \%$ pred US or $\geq 6 \%$ pred CAN (online suppl. table 2 ) from the time of diagnosis was associated with significantly increased risk of worsening (HR 4.86, $\mathrm{p}=0.0006$ for 6MWD in meters and \%pred US; HR 3.87, $\mathrm{p}=0.0027$ for \%pred CAN; table 4). Multivariate Cox proportional hazard analysis showed that the best independent predictors of worsening were baseline 6MWD \%pred US $\leq 63 \%$ and a 6 -month decline in $6 \mathrm{MWD} \%$ pred US $\geq 8 \%$, combined with baseline mPAP (table 5).

Early Decline in 6MWD after Diagnosis of PAH Predicts Clinical Worsening
Kaplan-Meier curves confirmed that patients with a decline in 6MWD (in meters or \%pred) 6 months after diagnosis experienced a significantly higher rate of worsening than patients with stable 6MWD $(\mathrm{p}<0.0001$; fig. 3). Within 18 months from the time of diagnosis, $69 \%$ of the subjects with a 6-month decline in 6MWD experienced clinical worsening.

Regarding the secondary end point, LTx-free survival, significant differences in 6MWD baseline values and 6-month $\triangle 6 \mathrm{MWD}$ were also found between survivors and nonsurvivors (online suppl. table 3 ). ROC analysis showed that baseline 6MWD values and 6-month declines were significant predictors of mortality (online suppl. table 4). Baseline 6MWD \%pred US was a slight- 


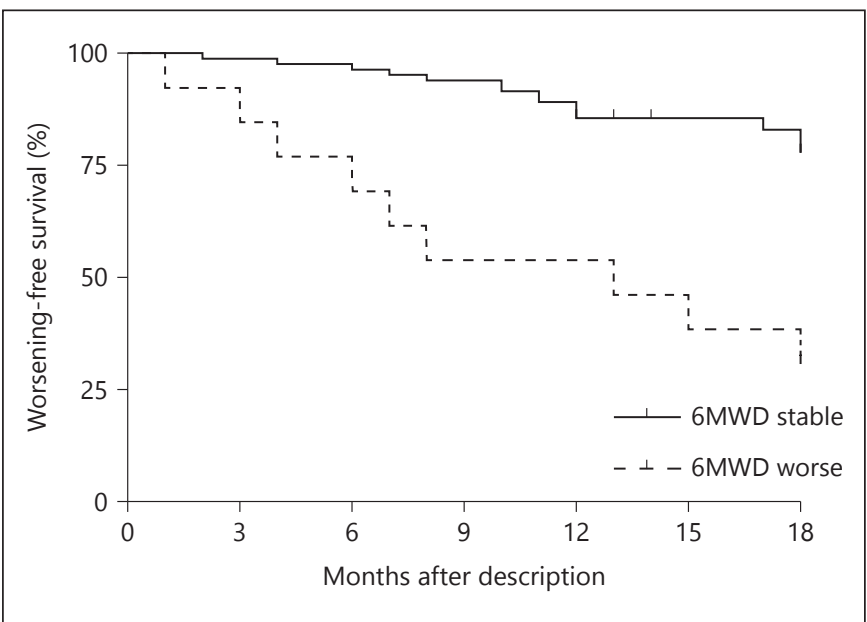

Fig. 3. A 6-month decline in 6MWD from the time of diagnosis predicts worsening. Kaplan-Meier worsening analysis grouped by 6MWD 6-month decline (either $\geq 35 \mathrm{~m}$ or $\geq 8 \%$ pred US - the results were identical). $\mathrm{p}<0.0001$ (log-rank).

Table 5. Predictors of clinical worsening according to the multivariate analysis

\begin{tabular}{llll}
\hline & HR & $95 \%$ CI & p value \\
\hline mPAP & 1.04 & $1.01-1.07$ & 0.0143 \\
6MWD \%pred US ( $\leq 63 \%)$ & 4.56 & $1.98-11.43$ & 0.0003 \\
$\begin{array}{l}\text { 6MWD \%pred US at 6-month } \\
\quad \text { decline }(\geq 8 \%)\end{array}$ & 7.21 & $2.76-18.04$ & 0.0002 \\
\hline
\end{tabular}

ly better predictor of the need for LTx or of mortality than 6MWD in meters and 6MWD \%pred CAN. However, the 6MWD \%pred provided no additional advantage over 6MWD in meters with respect to changes at 6 months (online suppl. tables 3-5). Clinical worsening was a strong risk factor for mortality during the observation period (HR 12.46; online suppl. table 5). Multivariate analysis (online suppl. table 6) identified a baseline $6 \mathrm{MWD} \%$ pred US of $\leq 63 \%$ and its 6 -month decline of $\geq 8 \%$ as independent predictors of mortality.

\section{Discussion}

In this study, we assessed whether short-term declines in 6MWD can predict clinical worsening in PAH. Longitudinal $\triangle 6 \mathrm{MWD}$ were evaluated from the time of diagnosis. Clinical worsening of PAH was defined with a con- servative approach based on widely accepted criteria, without considering subjective variables such as WHO FC. Our data show that early declines in 6MWD can predict future worsening of $\mathrm{PAH}$, including death and the need for LTx. Our study also evaluated, for the first time, the use of \%pred 6MWD, calculated using US and Canadian reference equations $[25,26]$. While baseline $6 \mathrm{MWD} \%$ pred provided some advantage in predicting outcomes, longitudinal changes were equivalent predictors of worsening when compared to 6MWD in meters. Declines in $6 \mathrm{MWD}$ of $\geq 35 \mathrm{~m}$ and $\geq 8 \%$ pred US at 6 months were identical in predicting worsening with high specificity but low sensitivity. Early postdiagnosis declines in 6MWD were also strong predictors of mortality.

The natural history of PAH is characterized by a 1-year mortality of $15 \%$ and a median survival of 2.8 years, in the absence of PAH-targeted therapy [17, 27]. In our population, $28 \%$ of the subjects experienced worsening within 18 months of diagnosis, and $20 \%$ died or received LTx over an average period of 30 months from diagnosis. Clinical worsening of PAH is emerging as a key measure of long-term outcome and was the main end point in a recent RCT that used macitentan treatment [14, 28, 29]. In our study, clinical worsening was defined according to widely recognized, objective criteria [18-22]. Since $6 \mathrm{MWD}$ continues to be the most commonly used objective test for monitoring the functional severity of PAH in clinical practice, it is critically important to establish its role in predicting worsening. Unfortunately, the reliability of $6 \mathrm{MWD}$ as a marker of disease worsening in PAH remains surrounded by controversy [7]. In the EARLY (Endothelin Antagonist Trial in Mildly Symptomatic Pulmonary Arterial Hypertension Patients) study, a significant effect of bosentan treatment on time to worsening was observed without a statistically significant $\triangle 6 \mathrm{MWD}$ [9]. A meta-analysis of 22 RCTs that included over 3,000 patients demonstrated no relationship between $\triangle 6 \mathrm{MWD}$ and clinical indicators of worsening, despite a significant treatment-associated impact on 6MWD and other key outcomes, including survival and hospitalization [8]. It is important to note that we included incident cases from the time of diagnosis only, but that the meta-analysis results were based on prevalent cases from RCTs in which patients were enrolled at different stages of the disease, meaning that subjects with severe or aggressive PAH may have been excluded. The rate of survival in incident and prevalent cases differs remarkably [30].

In several studies, a low baseline 6MWD has been shown to be associated with higher mortality, with cut-off 
values varying between $<165$ and $<332 \mathrm{~m}[15,16,18,31-$ 33]. We found a significant difference in both baseline $6 \mathrm{MWD}$ in meters and 6MWD \%pred in survivors versus nonsurvivors. In our study, there was also a significant difference in baseline 6MWD, in meters or \%pred, between progressors and nonprogressors. A previous study reported that a baseline $6 \mathrm{MWD}$ of $\leq 367 \mathrm{~m}$ was predictive of a greater risk of clinical worsening [14]. However, this particular study used a definition of worsening which incorporated a $15 \%$ reduction in $6 \mathrm{MWD}$ from baseline, the baseline was not necessarily defined as the time of diagnosis and the longitudinal changes were not considered [14].

As baseline 6MWD is generally measured at the time of diagnosis and before starting therapy, it is expected that a patient's subsequent 6MWD on therapy should improve. Indeed, the $\triangle 6 \mathrm{MWD}$ has been the primary outcome measurement in most of the RCTs on all the currently available PAH-targeted therapies. Metaanalyses of these RCTs found a mean improvement of $6 \mathrm{MWD}$ of between 22.4 and $42.8 \mathrm{~m}$ at $12-16$ weeks after the initiation of therapy $[7,16,34]$. However, longitudinal $\triangle 6 \mathrm{MWD}$ in response to $\mathrm{PAH}$ therapy has not been shown to be associated with survival benefit [22, 35]. Moreover, Gabler et al. [7] recently showed only a modest association between $\triangle 6 \mathrm{MWD}$ and clinical improvement, while Rubin et al. [36] showed a deterioration of $6 \mathrm{MWD}$ after starting sildenafil which was associated with poor survival. $\triangle 6 \mathrm{MWD}$ has also been shown to be predictive of patient-centered outcome measurements, such as health-related quality of life [35-37].

In this study, a decline in $6 \mathrm{MWD}$ of $\geq 35 \mathrm{~m} 6$ months after diagnosis predicted worsening with a high specificity (94\%). In contrast to the improvement expected once PAH therapy has been started, an early decline in 6MWD at this stage could identify subjects with more aggressive disease. The high rate of worsening, death or LTx suggests that the population included in this study had moderate to severe disease at baseline. Worsening strongly predicted mortality (HR 12.46); this was previously shown by Frost et al. [18].

As for the many physiological parameters, exercise capacity is dependent on anthropometric factors [38, 39] and \%pred may be a more robust method to control for individual differences compared to 6MWD in meters. The use of 6MWD \%pred versus 6MWD in meters in idiopathic pulmonary fibrosis $[40,41]$, chronic lung diseases [42] and congestive heart failure [43] better reflects patients' clinical status. In PAH, despite the long-stand-

Early Decline in 6MWD after Diagnosis

of PAH Predicts Clinical Worsening ing use of $6 \mathrm{MWD}$, it is largely unknown whether the $\%$ pred is a better marker of disease severity than 6MWD in meters; Lee et al. [13] showed that \%pred was not better for predicting mortality. Our data showed that, while only a small advantage was provided by baseline $6 \mathrm{MWD}$ \%pred over 6MWD in meters, 6-month declines in \%pred were equivalent to $6 \mathrm{MWD}$ in meters for predicting clinical worsening. However, multivariate analysis showed that the best independent predictors of worsening were a low baseline 6MWD \%pred US combined with its 6-month decline. 6MWD \%pred US and \%pred CAN also showed a better correlation with hemodynamic data than $6 \mathrm{MWD}$ in meters. Compared to the US reference equations, which perfomed slightly better in predicting outcome, the Canadian equations did not take into account patients' BMI [25]. From the literature, there appears to be wide variability between reference equations from different countries [44].

The main limitation of this study was its retrospective nature, which meant that patients with rapidly progressive disease may have been excluded from the analysis. Our center is, however, a regional tertiary referral center to which severe cases are often referred. Our results need to be confirmed in prospective studies. The lack of followup hemodynamic data in most of the patients was also a limitation.

\section{Conclusions}

Early decline in 6MWD in the first 6 months after diagnosis predicts clinically important worsening of $\mathrm{PAH}$ with high specificity. Therefore, despite recognized limitations, the regular assessment of 6MWD still provides valuable information for the clinical management of group I PAH. 6MWD \%pred obtained with the currently available equations did not provide a significant advantage over 6MWD in meters for predicting worsening or mortality. In addition, declines in 6MWD at 6 months after diagnosis predicted worsening with a poor sensitivity. 6MWD should therefore not be used in isolation for assessing patients with PAH. Outcomes can be predicted more accurately when the $6 \mathrm{MWD}$ is used in conjunction with a panel of other parameters.

\section{Acknowledgments}

This work by supported by funds from the Department of Medicine at the Western University. 


\section{References}

-1 Benza RL, Miller DP, Barst RJ, Badesch DB, Frost AE, McGoon MD: An evaluation of long-term survival from time of diagnosis in pulmonary arterial hypertension from the REVEAL registry. Chest 2012;142:448-456.

-2 Humbert M, Sitbon O, Chaouat A, Bertocchi M, Habib G, Gressin V, Yaïci A, Weitzenblum E, Cordier JF, Chabot F, Dromer C, Pison C, Reynaud-Gaubert M, Haloun A, Laurent M, Hachulla E, Cottin V, Degano B, Jaïs X, Montani D, Souza R, Simonneau G: Survival in patients with idiopathic, familial, and anorexigen-associated pulmonary arterial hypertension in the modern management era. Circulation 2010;122:156-163.

>3 Barst RJ, Rubin LJ, Long WA, McGoon MD, Rich S, Badesch DB, Groves BM, Tapson VF, Bourge RC, Brundage BH, Koerner SK, Langleben D, Keller CA, Murali S, Uretsky BF, Clayton LM, Jöbsis MM, Blackburn SD, Shortino D, Crow JW; Primary Pulmonary Hypertension Study Group: A comparison of continuous intravenous epoprostenol (prostacyclin) with conventional therapy for primary pulmonary hypertension. N Engl J Med 1996;334:296-301.

4 Simonneau G, Rubin LJ, Galie N, Barst RJ, Fleming TR, Frost AE, Engel PJ, Kramer MR, Burgess G, Collings L, Cossons N, Sitbon O, Badesch DB; PACES Study Group: Addition of sildenafil to long-term intravenous epoprostenol therapy in patients with pulmonary arterial hypertension: a randomized trial. Ann Intern Med 2008;149:521-530.

$\checkmark 5$ Provencher S, Sitbon O, Humbert M, Cabrol S, Jais X, Simonneau G: Long-term outcome with first-line bosentan therapy in idiopathic pulmonary arterial hypertension. Eur Heart J 2006;27:589-595.

6 Fritz JS, Blair C, Oudiz RJ, Dufton C, Olschewski H, Despain D, Gillies H, Kawut SM: Baseline and follow-up 6-min walk distance and brain natriuretic peptide predict 2-year mortality in pulmonary arterial hypertension. Chest 2013;143:315-323.

7 Gabler NB, French B, Strom BL, Palevsky HI, Taichman DB, Kawut SM, Halpern SD: Validation of 6-minute walk distance as a surrogate end point in pulmonary arterial hypertension trials. Circulation 2012;126: 349-356.

-8 Savarese G, Paolillo S, Costanzo P, D’Amore C, Cecere M, Losco T, Musella F, Gargiulo P, Marciano C, Perrone-Filardi P: Do changes of 6-minute walk distance predict clinical events in patients with pulmonary arterial hypertension? A meta-analysis of 22 randomized trials. J Am Coll Cardiol 2012;60:1192-1201.

-9 Frost AE, Langleben D, Oudiz R, Hill N, Horn E, McLaughlin V, Robbins IM, Shapiro S, Tapson VF, Zwicke D, DeMarco T, Schilz R, Rubenfire $\mathrm{M}$, Barst RJ: The 6-min walk test $(6 \mathrm{MW})$ as an efficacy endpoint in pulmonary arterial hypertension clinical trials: demonstration of a ceiling effect. Vasc Pharmacol 2005;43:36-39.
10 Frantz RP, McDevitt S, Walker S: Baseline NT-proBNP correlates with change in 6-minute walk distance in patients with pulmonary arterial hypertension in the pivotal inhaled treprostinil study TRIUMPH-1. J Heart Lung Transplant 2012;31:811-816.

11 van der Plas MN, Surie S, Reesink HJ, van Steenwijk RP, Kloek JJ, Bresser P: Longitudinal follow-up of six-minute walk distance after pulmonary endarterectomy. Ann Thorac Surg 2011;91:1094-1099.

12 Preston IR, Suissa S, Humbert M: New perspectives in long-term outcomes in clinical trials of pulmonary arterial hypertension. Eur Respir Rev 2013;22:495-502.

13 Lee WN, Peacock A, Johnson M: The role of per cent predicted 6-min walk distance in pulmonary arterial hypertension. Eur Respir J 2010;36:1294-1301.

14 Deboeck G, Scoditti C, Huez S,V achiéry JL, Lamotte M, Sharples L, Melot C, Naeije R: Exercise testing to predict outcome in idiopathic versus associated pulmonary arterial hypertension. Eur Respir J 2012;40:1410-1419.

15 Benza RL, Miller DP, Gomberg-Maitland M, Frantz RP, Foreman AJ, Coffey CS, Frost A, Barst RJ, Badesch DB, Elliott CG, Liou TG, McGoon MD: Predicting survival in pulmonary arterial hypertension insights from the Registry to Evaluate Early and Long-Term Pulmonary Arterial Hypertension Disease Management (REVEAL). Circulation 2010; 122:164-172.

16 Galiè N, Hoeper MM, Humbert M, Torbicki A, Vachiery JL, Barbera JA, Beghetti M, Corris P, Gaine S, Gibbs JS, Gomez-Sanchez MA, Jondeau G, Klepetko W, Opitz C, Peacock A, Rubin L, Zellweger M, Simonneau G; ESC Committee for Practice Guidelines (CPG): Guidelines for the diagnosis and treatment of pulmonary hypertension: the Task Force for the Diagnosis and Treatment of Pulmonary Hypertension of the European Society of Cardiology (ESC) and the European Respiratory Society (ERS), endorsed by the International Society of Heart and Lung Transplantation (ISHLT). Eur Heart J 2009;30:2493-2537.

17 McLaughlin VV, Archer SL, Badesch DB, Barst RJ, Farber HW, Lindner JR, Mathier MA, McGoon MD, Park MH, Rosenson RS, Rubin LJ, Tapson VF, Varga J: ACCF/AHA 2009 expert consensus document on pulmonary hypertension: a report of the American College of Cardiology Foundation Task Force on Expert Consensus Documents and the American Heart Association, developed in collaboration with the American College of Chest Physicians, American Thoracic Society and the Pulmonary Hypertension Association. J Am Coll Cardiol 2009;53:15731619.

-18 Frost AE, Badesch DB, Miller DP, Benza RL, Meltzer LA, McGoon MD: Evaluation of the predictive value of a clinical worsening definition using 2-year outcomes in patients with pulmonary arterial hypertension: a REVEAL registry analysis. Chest 2013;144:1521-1529.

19 Howard L: Prognostic factors in pulmonary arterial hypertension: assessing the course of the disease. Eur Respir Rev 2011;20:236-242.

20 Scholzel BE, Post MC, Plokker HT, Snijder RJ Clinical worsening during long-term followup in inoperable chronic thromboembolic pulmonary hypertension. Lung 2012;190: 161-167.

21 Vachiéry J, Yerly P, Huez S. How to detect disease progression in pulmonary arterial hypertension. Eur Respir Rev 2012;21:40-47.

22 Nickel N, Golpon H, Greer M, Knudsen L, Olsson K, Westerkamp V, Welte T, Hoeper MM: The prognostic impact of follow-up assessments in patients with idiopathic pulmonary arterial hypertension. Eur Respir J 2012; 39:589-596.

23 American Thoracic Society: Standardization of spirometry, 1994 update. Am J Respir Crit Care Med 1995;152:1107-1136.

24 ATS Committee on Proficiency Standards for Clinical Pulmonary Function Laboratories: ATS statement: guidelines for the six-minute walk test. Am J Respir Crit Care Med 2002; 166:111-117.

25 Hill K, Wickerson LM, Woon LJ, Abady AH, Overend TJ, Goldstein RS, Brooks D: The 6-min walk test: responses in healthy Canadians aged 45 to 85 years. Appl Physiol Nutr Metab 2011;36:643-649.

26 Enright PL, Sherrill DL: Reference equations for the six-minute walk in healthy adults. Am J Respir Crit Care Med 1998;158:1384-1387.

27 D’Alonzo GE, Barst RJ, Ayres SM, Bergofsky $\mathrm{EH}$, Brundage BH, Detre KM, Fishman AP, Goldring RM, Groves BM, Kernis JT, Levy PS, Pietra GG, Reid LM, Reeves JT, Rich S, Vreim CE, Williams GW, Wu M: Survival in patients with primary pulmonary hypertension. Results from a national prospective registry. Ann Intern Med 1991;115:343-349.

28 Galiè N, Simonneau G, Barst RJ, Badesch D, Rubin L: Clinical worsening in trials of pulmonary arterial hypertension: results and implications. Curr Opin Pulm Med 2010;16: S11-S19.

29 Pulido T, Adzerikho I, Channick RN, Delcroix M, Galiè N, Ghofrani HA, Jansa P, Jing ZC, Le Brun FO, Mehta S, Mittelholzer CM, Perchenet L, Sastry BK, Sitbon O, Souza R, Torbicki A, Zeng X, Rubin LJ, Simonneau G; SERAPHIN Investigators: Macitentan and morbidity and mortality in pulmonary arterial hypertension. N Engl J Med 2013;369:809-818.

30 Humbert M, Sitbon O, Yaici A, Montani D, O'Callaghan DS ,Jaïs X, Parent F, Savale L, Natali D, Günther S, Chaouat A, Chabot F, Cordier JF, Habib G, Gressin V, Jing ZC, Souza R, Simonneau G; French Pulmonary Arterial Hypertension Network: Survival in incident and prevalent cohorts of patients with pulmonary arterial hypertension. Eur Respir J 2010;36:549-555. 
31 Miyamoto S, Nagaya N, Satoh T, Kyotani S, Sakamaki F, Fujita M, Nakanishi N, Miyatake $\mathrm{K}$ : Clinical correlates and prognostic significance of six-minute walk test in patients with primary pulmonary hypertension: comparison with cardiopulmonary exercise testing. Am J Respir Crit Care Med 2000;161:487-492.

- 32 Sitbon O, Humbert M, Nunes H, Parent F, Garcia G, Hervé P, Rainisio M, Simonneau G: Long-term intravenous epoprostenol infusion in primary pulmonary hypertension: prognostic factors and survival. J Am Coll Cardiol 2002;40:780-788.

-33 Richter MJ, Tiede H, Morty RE, Voswinckel R, Seeger W, Schulz R, Ghofrani HA, Reichenberger F: The prognostic significance of inspiratory capacity in pulmonary arterial hypertension. Respiration 2014;88:24-30.

-34 Macchia A, Marchioli R, Marfisi R, Scarano M, Levantesi G, Tavazzi L, Tognoni G: A meta-analysis of trials of pulmonary hypertension: a clinical condition looking for drugs and research methodology. Am Heart J 2007; 153:1037-1047.

35 Mathai SC, Puhan MA, Lam D, Wise RA: The minimal important difference in the 6-minute walk test for patients with pulmonary ar- terial hypertension. Am J Respir Crit Care Med 2012;186:428-433.

-36 Rubin LJ, Badesch DB, Fleming TR, Galiè N, Simonneau G, Ghofrani HA, Oakes M, Layton G, Serdarevic-Pehar M, McLaughlin VV, Barst RJ; SUPER-2 Study Group: Long-term treatment with sildenafil citrate in pulmonary arterial hypertension: the SUPER-2 study. Chest 2011;140:1274-1283.

37 Gilbert C, Brown MC, Cappelleri JC, Carlsson M, McKenna SP: Estimating a minimally important difference in pulmonary arterial hypertension following treatment with sildenafil. Chest 2009;135:137-142.

38 Oudiz RJ, Barst RJ, Hansen JE, Sun XG, Garofano $\mathrm{R}, \mathrm{Wu} \mathrm{X}$, Wasserman K: Cardiopulmonary exercise testing and six-minute walk correlations in pulmonary arterial hypertension. Am J Cardiol 2006;97:123-126.

39 Chuang ML, Lin IF, Wasserman K: The body weight-walking distance product as related to lung function, anaerobic threshold and peak VO2 in COPD patients. Respir Med 2001;9: 618-626.

40 Mura M, Ferretti A, Ferro O, Zompatori M, Cavalli A, Schiavina M, Fabbri M: Functional predictors of exertional dyspnea, 6-min walk- ing distance and HRCT fibrosis score in idiopathic pulmonary fibrosis. Respiration 2006; 73:495-502.

41 Mura M, Porretta MA, Bargagli E, Sergiacomi G, Zompatori M, Sverzellati N, Taglieri A, Mezzasalma F, Rottoli P, Saltini C, Rogliani P: Predicting survival in newly diagnosed idiopathic pulmonary fibrosis: a 3-year prospective study. Eur Respir J 2012;40:101-109.

42 Güngör G, Karakurt Z, Adıgüzel N, Aydin RE, Balci MK, Saltürk C, Sancar R, Solmaz S, Moçin ÖY: The 6-minute walk test in chronic respiratory failure: does observed or predicted walk distance better reflect patient functional status? Respir Care 2013;58:850-857.

43 Balashov K, Feldman DE, Savard S, et al: Percent predicted value for the 6-minute walk test: using norm-referenced equations to characterize severity in persons with CHF. J Card Fail 2008;14:75-81.

44 Casanova C, Celli B, Barria P, Casas A, Cote C, de Torres JP, Jardim J, Lopez MV, Marin JM, Montes de Oca M, Pinto-Plata V, Aguirre-Jaime A; Six Minute Walk Distance Project (ALAT): The 6-min walk distance in healthy subjects: reference standards from seven countries. Eur Respir J 2011;37:150-156.

\section{Erratum}

The authors of the article entitled 'Long-term data from the Swiss pulmonary hypertension registry' [Respiration 2015;89:127-140, DOI: 10.1159/000370125] wish to publish the following correction. On page 127, the name of an author has been published incorrectly: Guido Domeninghetti should read Guido Domenighetti. The correct author list should be as follows:

Séverine Mueller-Mottet ${ }^{\mathrm{a}}$ Hans Stricker $^{\mathrm{b}}$ Guido Domenighetti ${ }^{\mathrm{c}}$ Andrea Azzola ${ }^{\mathrm{d}}$ Thomas Geiser $^{\mathrm{e}}$ Markus Schwerzmann ${ }^{\mathrm{f}}$ Daniel Weilenmann ${ }^{\mathrm{g}}$ Otto Schoch $^{\text {h }}$ Jean-Marc Fellrath ${ }^{\mathrm{i}}$ Thierry Rochat $^{\mathrm{j}}$ Frederic Lador $^{\mathrm{j}}$ Maurice Beghetti ${ }^{\mathrm{k}}$ Laurent Nicod $^{\mathrm{l}}$ John-David Aubert $^{\mathrm{l}}$ Vladimir Popov ${ }^{\mathrm{m}}$ Rudolf Speich $^{\mathrm{a}}$ Stephan Keusch ${ }^{\mathrm{a}}$ Elisabeth Hasler ${ }^{\mathrm{a}}$ Lars C. Huber ${ }^{\mathrm{a}}$ Peter Grendelmeier ${ }^{\mathrm{n}}$ Michael Tamm $^{\mathrm{n}}$ Silvia Ulrich ${ }^{\mathrm{a}}$

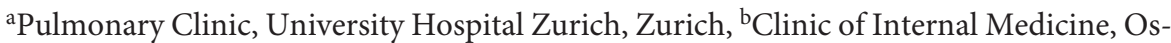
pedale La Carità, and ${ }^{\mathrm{C} P u l m o n a r y ~ C l i n i c, ~ C a n t o n a l ~ H o s p i t a l ~ L o c a r n o, ~ L o c a r n o, ~}{ }^{\mathrm{d}}$ Pulmonary Clinic, Cantonal Hospital Lugano, Lugano, ${ }^{e}$ Pulmonary Clinic and ${ }^{\mathrm{f}}$ Division of Cardiology, University Hospital Bern, Bern, gDivision of Cardiology and hPulmonary

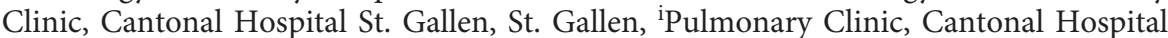
Neuchâtel, Neuchâtel, jPulmonary Clinic, University Hospital Geneva, and kPediatric Cardiology Unit, University Children's Hospital, Geneva, ${ }^{1}$ Pulmonary Clinic, University Hospital Lausanne, Lausanne, ${ }^{m}$ Pulmonary Clinic, Cantonal Hospital Lucerne, Lucerne, and ${ }^{\mathrm{n}}$ Pulmonary Clinic, University Hospital Basel, Basel, Switzerland

Early Decline in 6MWD after Diagnosis of PAH Predicts Clinical Worsening 